\title{
Market and regulatory barriers to electrical energy storage innovation
}

\author{
Giorgio Castagneto Gissey ${ }^{a}$, Paul E. Dodds ${ }^{a}$, Jonathan Radcliffe ${ }^{b}$ \\ a UCL Energy Institute, University College London \\ ${ }^{\mathrm{b}}$ Birmingham Energy Institute, University of Birmingham \\ * Corresponding Author: Giorgio Castagneto Gissey; +44 (0)20 3108 597; g.castagneto- \\ gissey@ucl.ac.uk. Address: UCL Energy Institute; Central House; 14 Upper Woburn Place; \\ London; WC1H 0NN; United Kingdom
}

Energy storage has been identified as a priority technology for innovation. However, the rapidly developing family of storage technologies will find it difficult, under the current regulatory regimes, to compete with conventional generators for the provision of electricity system services, and this is likely to impede innovation. This paper analyses and categorizes 16 investment barriers hindering the near-term deployment of energy storage technologies in electricity markets, which are related to four regulatory and public attitudes barriers.

The most important regulatory barrier is the current classification of storage as a generation asset, despite it being unable to provide a positive net flow of electricity, which is used to justify double network usage charges. The merit order design of balancing and ancillary markets makes it difficult for storage technologies to recoup their relatively high capital cost, while capacity markets penalize their limited discharge duration. Network companies are in the best position to realize the system value of storage, but their ownership may only be acceptable if system operation is made independent of network operation.

Current initiatives to address these issues include flexible connection agreements and the development of enhanced frequency response and aggregate fast reserve services. However, to remove the identified barriers, a market structure that valued the flexibility offered by storage, viewing it as complementing rather than competing with network and generation assets, would be required.

Keywords: energy storage; electricity market; market regulation; regulatory barriers.

\author{
Abbreviations: \\ TSO \\ TNUOS \\ ISO \\ DNO \\ DSO \\ DUoS
}




\section{Contents}

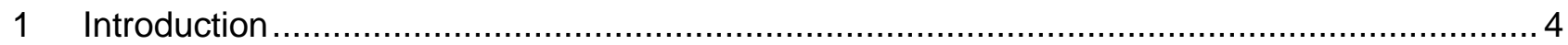

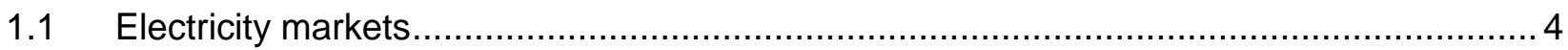

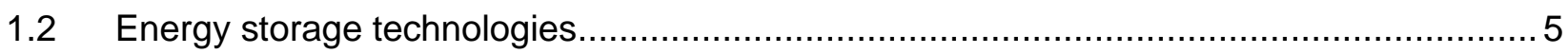

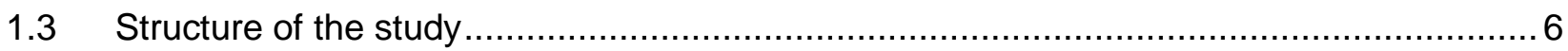

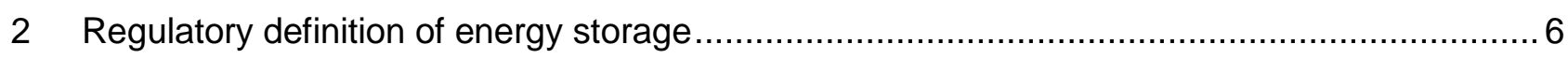

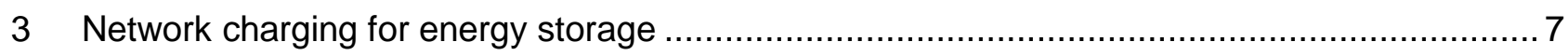

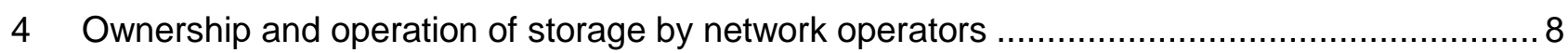

4.1 Alternative transmission network business models ................................................. 9

4.2 Alternative distribution network business models ....................................................... 10

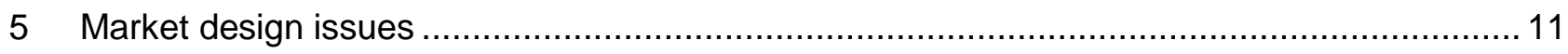

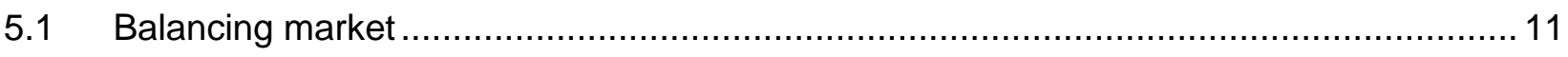

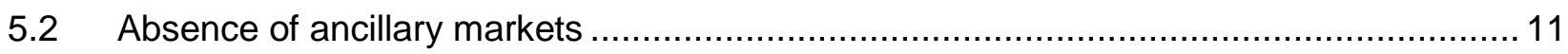

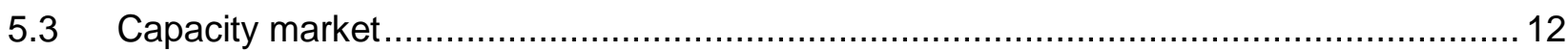

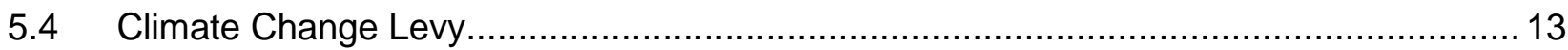

6 Categorization of barriers to energy storage deployment .............................................. 13

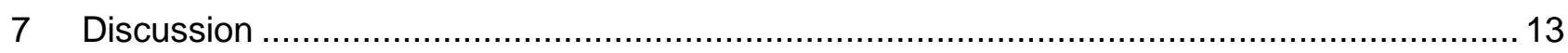

7.1 Network operator ownership of storage assets ............................................... 15

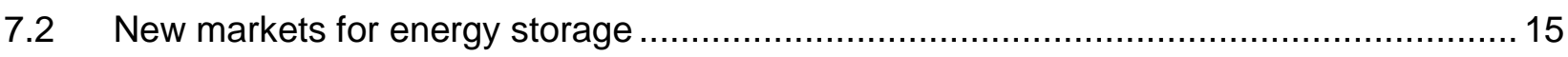

7.3 Subsidies for energy storage deployment ....................................................... 16

Limitations to this analysis and future work .............................................................. 16

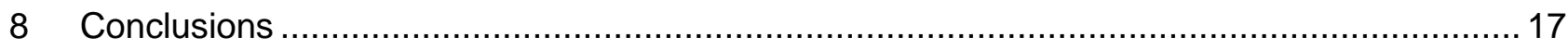

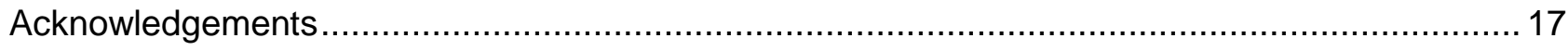

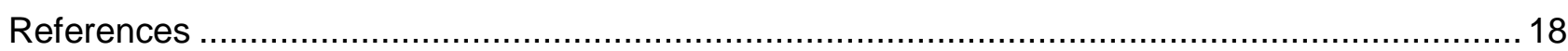




\section{Highlights}

1. Innovation in new technologies is underpinned by learning through deployment.

2. We review market barriers to deploying energy storage technologies.

3. Four 'exogenous' barriers underpin 16 more general barriers to deployment.

4. The definition of storage as generation is the most important barrier.

5. Several countries are promoting initiatives to encourage storage deployment. 


\section{Introduction}

The term 'electrical energy storage' encompasses a substantial number of diverse technologies whose aim is to store energy, then to release it later in the form of electricity. Most energy storage capacity worldwide is currently comprised of pumped hydropower plants that, due to their economies of scale and large-scale generation capabilities, have traditionally provided a number of system balancing services.

Historically, energy storage in the electricity system has primarily focused on precursors to electricity (e.g. coal; natural gas), with flexible generation capacity being used to meet demand peaks. As weather-dependent renewables and inflexible nuclear power plants take a greater share of the electricity generation markets in the future, frequent excess supply peaks at times of low demand could occur. Electrical energy storage technologies can store this excess energy and use it to meet demand peaks, providing stability and increasing the robustness of low-carbon electricity systems [1]. Storage is unique because it decouples the generation of electricity from its consumption and, in so doing, can help to manage the grid better, optimize the use of current resources, and integrate large-scale renewables.

This potential role for energy storage has led to it being identified as a key technology for the future [2]. For example, the UK Government has identified energy storage as one of 'Eight Great Technologies' for the UK [3] and has committed to a program of research and innovation [4]. Yet successful innovation that reduces technology costs requires the deployment of technologies to underpin learning-by-doing [5]. If this innovation drive is to be successful, energy storage will have to be able to compete with other generation in electricity markets.

Energy storage competes with other generation to sell electricity in markets [6]. A combination of high capital costs and regulatory barriers mean that energy storage is uncompetitive in most markets at present. In several countries, governments are considering options to increase energy storage deployment through regulatory changes [e.g. 7, 8].

This paper identifies and categorizes the barriers to energy storage in existing electricity markets and considers how these could be addressed to encourage an appropriate level of technology innovation. We study the regulatory definition of energy storage, network barriers, issues related to the ownership and operation of storage by network operators, as well as balancing, ancillary, and capacity market design issues.

\subsection{Electricity markets}

Until the 1990s, most electricity companies were state-owned and prices were heavily regulated. Since liberalization in most OECD countries, most high-volume consumers have bought electricity through bilateral contracts [9], while other generation has been controlled though a series of markets. The complex price behavior in these markets has reflected the historically-high cost of both storage and spare generation capacity, high demand fluctuations, and a political need for the system to supply all demands at all times with high reliability.

An important large-scale market for electrical energy storage technologies in the long term is the balancing market, where investments would be monetized through reserve replacement. Yet energy storage could also offer services in other ancillary markets for fast reserve and grid stability services [10], where they might be more competitive in the near term. These markets are listed for the UK in Table 1. Providing multiple and simultaneous services to several markets could greatly increase revenues and underpin business cases [11], but is difficult to achieve due to operational practicalities. It is also possible that storage may play an important role in the energy wholesale market too, in the longer term, and aggregators are expected to help integrate smaller-scale technologies. 


\begin{tabular}{|c|c|c|c|}
\hline Service & $\begin{array}{l}\text { Response } \\
\text { duration }\end{array}$ & Timescale & Role of storage \\
\hline RoCoF control & $<0.5 \mathrm{sec}$ & $<15 \min$ & Charging or discharging in response to frequency deviations \\
\hline $\begin{array}{l}\text { Frequency } \\
\text { containment }\end{array}$ & $<10 \mathrm{sec}$ & $10-30 \mathrm{sec}$ & $\begin{array}{l}\text { (Dis)charging in response to loss of generation or load that affects the system } \\
\text { frequency }\end{array}$ \\
\hline $\begin{array}{l}\text { Frequency } \\
\text { replacement }\end{array}$ & $<2 \min$ & $<30 \mathrm{~min}$ & $\begin{array}{l}\text { (Dis)charging in response to loss of generation or load, with the aim of red that } \\
\text { affects the system frequency }\end{array}$ \\
\hline Voltage support & $<1 \mathrm{sec}$ & $1-60 \mathrm{sec}$ & $\begin{array}{l}\text { (Dis)charging reactive power to stabilize voltage in the transmission and/or } \\
\text { distribution system }\end{array}$ \\
\hline Operating reserve & $240 \mathrm{~min}$ & 2-24 hour & Discharging at times of high demand in preference to flexible generation \\
\hline Black start & N/A & N/A & Contributing to restarting an electricity system following a total failure \\
\hline
\end{tabular}

Table 1. Services that energy storage could provide to the UK electricity system in the current market structure. RoCoF is the Rate of Change of Frequency.

More widely, energy storage technologies could contribute across the electricity system, including to generation (balancing; reserve power), transmission (frequency control; investment deferral), distribution (voltage control; capacity support), and end users (peak-shaving; cost reduction and management) [12].

Changes to electricity markets to encourage energy storage would have two broad aims: (i) to encourage innovation to reduce prices, in the short term; and, (ii) to aim for the optimum deployment that reflects the increasing value of energy storage to the system, in the long term. The likely value of storage in the wider energy system in the future is not well understood. Moreover, the potential role and competitiveness of energy storage in new markets is also not well understood, partly because the temporal resolution of existing market models is inadequate to understand the multiple benefits that storage might offer to underpin the business cases for new deployments [13].

\subsection{Energy storage technologies}

At present, pumped-hydro storage represents $99 \%$ of total storage power capacity worldwide, but has only a small role in most systems. For example, the UK has $80 \mathrm{GW}$ generation capacity but only $3 \mathrm{GW}$ storage capacity [14]. A range of alternative energy storage family of technologies have been developed that have a wide range of physical characteristics [15]. They are at very different levels of maturity, with only a few approaching commercialization. The wide diversity of energy storage technologies creates a challenge for regulators to design market structures and price signals that encourage appropriate levels of innovation across technologies and capture the diversity of the benefits that they can provide to the wider system.

Energy storage technologies can be characterized by power rating and discharge duration, as shown in Figure 1. Technologies with long discharge duration and high power rating, such as pumped-hydro storage, are able to provide services such as balancing to the transmission system operator (TSO) and energy management. Those with shorter discharge duration and lower power rating, including flywheels, supercapacitors or batteries, are more appropriate for the provision of services to distribution network operators (DNOs) and residential users. The relative importance of these diverse technologies in the long term will depend on the future evolution of low-carbon electricity systems. 


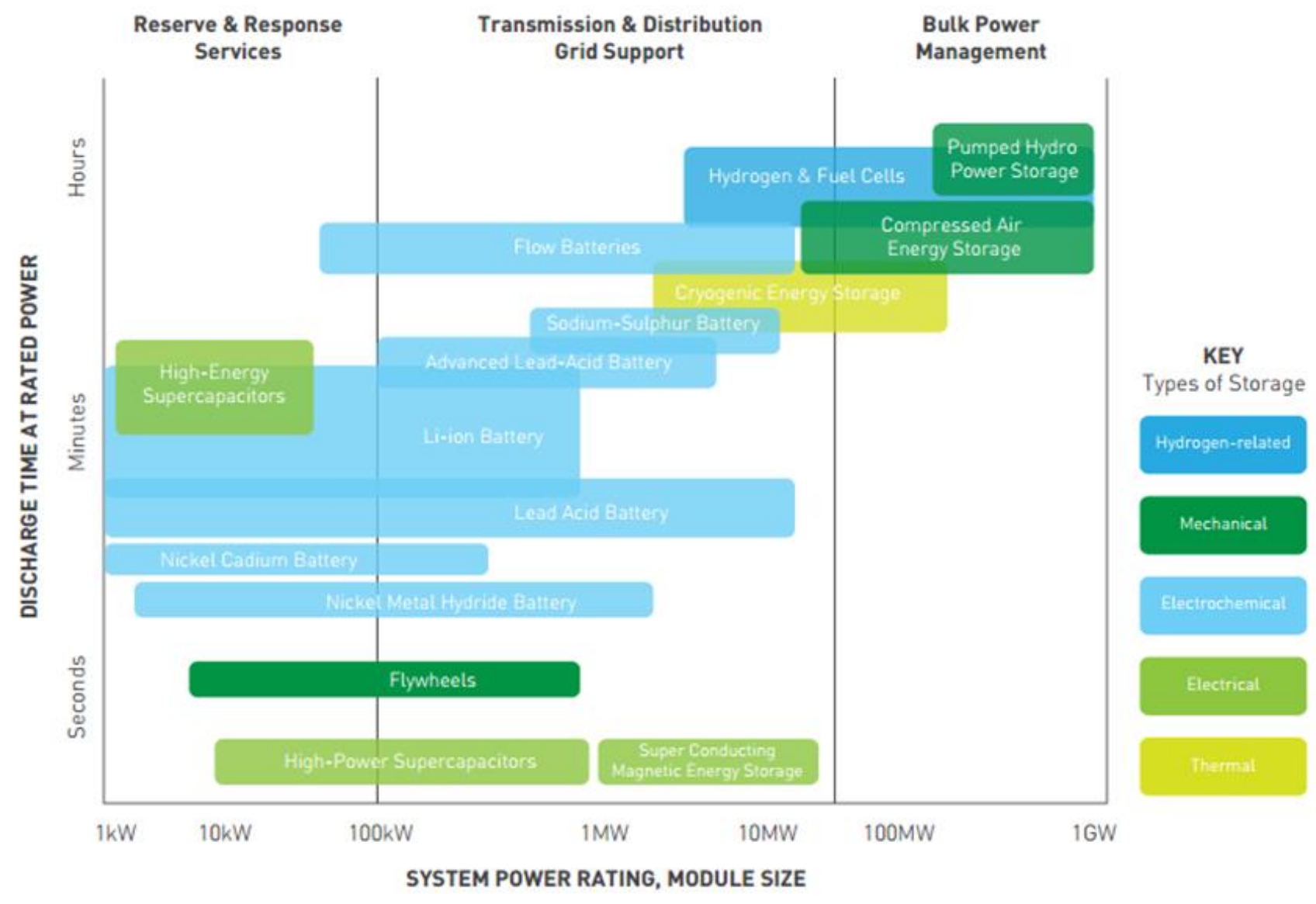

Figure 1. Key electricity storage technology options to support the system by discharge time (seconds to hours) and system power rating ( $k W$ to GW) [16].

\subsection{Structure of the study}

Reflecting the UK Government's focus on innovation and hence the need for energy storage investments in the near term, this paper analyses the barriers to energy storage in the UK electricity market. Yet, most of the presented issues apply equally to other markets.

Section 2 concentrates on the role of storage within the electricity system and on the issues deriving from the regulatory definition of energy storage. It considers the ownership and operation of storage by system/network operators, business models and their implications, and general market design issues. Current policy initiatives are then detailed in Section 3. Section 4 discusses our findings, while Section 5 provides our concluding remarks.

\section{Regulatory definition of energy storage}

Storage is classified as a generation asset in most electricity markets, including the UK, where there is neither an activity nor an asset class definition for energy storage. Generation assets have a very broad definition in the UK Electricity Act 1989 as "the generation of electricity at a relevant place", and EU Directive 2009/72/EC similarly refers to generation as "assets that produce electricity". The UK Electricity Order 2001 extends these definitions by stating that the technology "generates or is capable of generating electricity". From a technical perspective, energy storage technologies can generate electricity, so are covered by these definitions. However, storage cannot generate a positive net flow of electricity, and classification as generation does not recognize the potential contribution of storage to moving electricity from periods of low demand to meet peak demands. 
A definition of energy storage has been proposed by the European Commission as the "act of deferring an amount of the energy that was generated to the moment of use, either as final energy or converted into another energy carrier" [17]. Another definition from the UK's Electricity Storage Network ${ }^{1}$ defines electricity storage as "the conversion of electrical energy into a form of energy which can be stored, the storing of that energy, and the subsequent reconversion of that energy back into electrical energy" [18], but such a definition could unintentionally include equipment such as network appliances.

We propose the following definition of a storage asset that accounts for the zero (or negative) net flow of electricity from the device, which could better reflect the effective burden of storage on the system:

"A means of converting imported electricity into a form of energy that is stored and can be reconverted into electrical energy, that is unable to produce a positive net flow of electrical energy from the device, and for which, given sufficient storage capacity headroom and footroom, the timing of imports and exports can, under normal operating conditions, be controlled independently of each other and the voltage at the point of connection to the power system."

The reference to control of the timing of imports and exports is intended to ensure that network assets such as capacitors and transformers are not caught by this definition. Supercapacitors have been identified as potentially important storage technologies for the future [19].

\section{Network charging for energy storage}

Despite large increases in research funding for storage, and increasingly large deployments of variable renewable generation, many electricity markets have seen little EES deployment to date [20]. This may largely be attributed to the low rewards that storage operators receive for the services they provides to the wider network, especially in markets that have undergone significant restructuring and liberalization.

Storage could provide ancillary services to the electricity networks in order to reduce peak loads, but this does not tend occur in some countries such as the UK. One reason is the cost of Transmission Network Use of System (TNUoS) charges and Distribution Use of System (DUoS) charges, which are designed to recoup infrastructure costs from consumers and suppliers (Table 2). In the UK, storage providers must pay double TNUoS tariffs for their role as both generators and consumers, when operating in charge and discharge modes, as well as DUoS charges. If the generator is $<100 \mathrm{MW}$, which includes most novel storage technologies, then they are not liable to pay TNUoS but must still pay DUoS tariffs [21]. Both transmission and distribution network tariffs offer potential revenue streams that could help storage realize value. The DUoS charge is banded by time of day, which offers an arbitrage potential for storage. The TNUoS tariff also offers potential revenue by reducing peak demand during the Triad periods [22]. ${ }^{2}$ Whether these revenue streams could be realized, and storage use optimized, would depend on how storage were controlled and storage services sold within the electricity system.

More generally, these double charges arguably do not reflect the complementary benefits of storage to the networks for balancing the wider electricity system, as the former moves electricity in time and the latter across space. In most cases, storage is used for balancing, which does not contribute to congestion but instead relieves it. The removal of barriers would ideally be based on

\footnotetext{
1 The Electricity Storage Network (ESN) is considered by the UK Government to be the UK's main trade body for electricity storage.

2 Triads are defined as the three half-hours of highest demand on the GB electricity transmission system between November and February each year. National Grid identifies peak electricity demand at these three points in order to minimise energy consumption and set charges for transmission system use.
} 
its potential contribution to the electricity system. There is a fundamental debate about the role of storage, in particular whether it provides an add-on service, in competition on the margin with networks and generation, or whether it complements networks and generation.

EU regulations do not force member countries to regulate energy storage technologies in the same way. A number of member states (Czech Republic, Spain, Italy, Lithuania, Poland, Portugal and Slovakia) do not impose grid fees to storage plants, while other states (Austria, Belgium and Greece) apply fees to storage for both charging and discharging. The lack of common EU-wide legislation effectively leaves each state to determine charging policies for each electricity system asset [23]. This regulatory heterogeneity could encourage energy storage investments in member states with no grid fees that then export to other member states with high grid fees. The result would be an inefficient and zonally sub-optimal allocation of storage resources across the EU. Although no EU-wide attempt has been made to harmonies grid access fees, this would provide fairer and more extensive competition for storage technologies and other generators across European electricity systems.

Defining a new asset class for energy storage would enable the implementation of alternative charging regimes in those countries that treat storage as generation and apply high grid fees. One approach would be charging models and network connection tariffs that reflect the size, use and location of the storage connection [12]. However, the influence of the choice of location on the value of storage to the system is not well understood.

\begin{tabular}{|c|c|c|}
\hline Location & Charges & Charging arrangements \\
\hline Generation & $\begin{array}{l}\text { Transmission entry } \\
\text { capacity (TEC) payable } \\
\text { via TNUoS by } \\
\text { generators and } \\
\text { consumers to National } \\
\text { Grid, and distribution } \\
\text { use through DUoS. }\end{array}$ & $\begin{array}{l}\text { Paid at the generation TNUoS tariffs set by National Grid, which are } \\
\text { charged on a maximum-capacity basis. This means that generators with } \\
200 \mathrm{MW} \text { of TEC who only generated at a maximum rate of } 100 \mathrm{MW} \\
\text { during the year would still be charged for the full } 200 \mathrm{MW} \text { of TEC. Small } \\
\text { (<100 MW in England and Wales) generators do not pay TNUoS if they } \\
\text { do not significantly affect the transmission network. DUoS charges are } \\
\text { payable by generators and suppliers to Distribution Network Operators } \\
\text { (DNOs) for using the distribution network. }\end{array}$ \\
\hline Distribution & $\begin{array}{l}\text { DUoS paid by } \\
\text { generators, suppliers, } \\
\text { and major consumers } \\
\text { for use of distribution } \\
\text { network, to DNO. }\end{array}$ & $\begin{array}{l}\text { If DNOs suspect that the embedded generator may have a significant } \\
\text { impact on the transmission network, they should contact National Grid, } \\
\text { and will pay TNUoS. Distribution-connected small generators are liable to } \\
\text { pay DUoS, or a charge levied by a DNO for the transmission of electricity } \\
\text { through its local network, but not TNUoS. }\end{array}$ \\
\hline Consumer & $\begin{array}{l}\text { TNUoS payable by } \\
\text { generators and } \\
\text { consumers to National } \\
\text { Grid due to charging if } \\
\text { device is greater than } \\
100 \mathrm{MW} \text {. }\end{array}$ & $\begin{array}{l}\text { Different for half-hourly }(\mathrm{HH}) \text { metered and non-half-hourly }(\mathrm{NHH}) \text { metered } \\
\text { customers. Customers with sufficiently high peak demand are obliged to } \\
\text { have a } \mathrm{HH} \text { meter. Charges for a HH metered customer are based on their } \\
\text { demand during three half-hour periods of greatest demand in evenings } \\
\text { between November and February, known as the Triad, and equals } \\
\text { average demand during the Triad periods multiplied by the tariff for their } \\
\text { zone. NHH customers are charged for the sum of their total consumption } \\
\text { between 16:00 and 19:00 every day over a year, multiplied by the zonal } \\
\text { tariff. }\end{array}$ \\
\hline
\end{tabular}

Table 2. Regulation of UK network charges by their size and location in the electricity system.

\section{Ownership and operation of storage by network operators}

If networks were to invest in storage assets, then it might be possible to realize their complementary strengths to support the electricity system. However, the unbundling obligations in EU Directive 2009/72/EC, which require the separation of entities in the vertically integrated 
system, restrict the operation and ownership of storage technologies by DNOs ${ }^{3}$ to small devices. Transmission System Operators (TSOs) are not allowed to own or operate any form of generation and, by extension, energy storage. There is a debate within the European Commission about whether DNOs or TSOs should be allowed to own energy storage assets [24], which creates considerable uncertainty for new investments in storage technologies.

There is a strategic regulatory question about the extent to which the system operator should directly operate energy storage. If the system operator does not control storage, it is likely that the imperfect information about electricity demands that is available to the storage provider would mean that they would be unable to sell sufficient balancing and ancillary services at the optimal time to realize its system value, which would make storage less competitive and would impede investments. The system operator is therefore best placed to optimize the use of storage technologies to balance the system. The scope for a choice to be made between investing in storage at a given location instead of extra network capacity could be widened where it can be shown that storage is the most economic option taking into account all the services it can offer.

\subsection{Alternative transmission network business models}

Although their choices are restricted by regulation, network companies are profit-maximizing businesses that are likely to view revenue-creating network capacity expansion or interconnection more favorably than storage investments. An Independent System Operator (ISO) could be created that were legally separate from owner and operator of the transmission networks. If regulations were introduced to ring-fence these independent operators from directly interacting with network operators when allocating flexibility, this might underpin investments into storage where appropriate.

Three possible business models have been proposed for TSOs and these are described in Table 3. The 'Ownership unbundling' and ISO models necessitate separating TSO activities from any activities that are related to the market. Such provision forbids the TSO from holding generation assets, and hence any form of energy storage. While the ITO model permits common ownership, which is currently prohibited, it should be accompanied by complete independence and ring fencing from a legal operational perspective to avoid any distortion of competition.

Italy and Belgium similarly have more flexible approaches to TSO ownership than most countries. Italy allows TSOs to build and operate batteries, if this can be justified with a cost-benefit analysis that shows the cost-efficiency of storage compared to alternatives. Belgium similarly allows TSOs ownership of storage devices if this does not prevent the competitive functioning of markets [25] ${ }^{4}$. The key challenge for transmission network ownership of storage is to ensure competitive generation markets. This is a difficult challenge since the cost of storage is dominated by the capital cost, and once the storage asset is deployed, it is difficult to justify not using it.

\begin{tabular}{ll}
\hline \multicolumn{1}{c}{ Business model } & \multicolumn{1}{c}{ Description } \\
\hline Ownership unbundling & $\begin{array}{l}\text { This option requires full ownership separation in order to safeguard the independence } \\
\text { of network ownership from potential interests in supply and generation. }\end{array}$ \\
$\begin{array}{l}\text { Independent system } \\
\text { operator (ISO) }\end{array}$ & $\begin{array}{l}\text { An independent TSO free of interests in generation or supply operates the system is } \\
\text { required. At the same time, ownership of the transmission network is allowed to } \\
\text { remain within the transmission sector. } \\
\text { Ownership and operation of the asset are allowed to remain within the same sector; } \\
\begin{array}{l}\text { Independent } \\
\text { transmission operator } \\
\text { (ITO) }\end{array}\end{array} \quad \begin{array}{l}\text { however, the ITO must be guaranteed to be operationally independent with stringent } \\
\text { rules on ring fencing. }\end{array}$ \\
\hline
\end{tabular}

Table 3. Proposed business models for TSOS in terms of ownership and operation of storage assets [25].

\footnotetext{
${ }^{3}$ DNOs are not required to abide to these ownership unbundling regulations; rather, they have legal, accounting and functional unbundling requirements in order to guarantee the operational independence of distribution services from other activities in the system, if they serve less than 100,000 connected consumers.

${ }^{4}$ Italian decree law 93/11, Art. 36, par.4 16; Belgian Electricity Act, Article 9(1).
} 


\subsection{Alternative distribution network business models}

For DNO-owned storage in the UK, US, and other major world markets, a third party must handle electricity flows when storage is used to support the network or to provide broader system-wide services. The third party must be contracted and mentioned in the business case for the storage technology, which complicates the business case. This third party could be either an independent entity or another DNO that is appropriately ring-fenced from engaging in such activities. Such arrangements can be complex, leading to a barrier to entry for new storage technologies to the market.

Although large-scale storage facilities are bound by generation licenses in the UK, the Electricity Order 2001 allows for the exemption of "small" storage with output under 50 MW [26]. Exemption from the standard generation license is allocated on a plant-by-plant basis, imposing potentially significant delays on storage-related projects [25] .

If a DNO decided to deploy storage using the generation license exemption, it would be overspending its capital allowance, but would only receive little income via the restrictive de minimis requirements [26]. ${ }^{5}$ If a DNO used a 'standard' approach to justify its use of storage (i.e. conventional asset replacement, or reinforcement), its activity would need to be assessed based on the expected efficient costs for the substitute asset type, which would feed into its revenue and the regulatory asset value. This assessment reflects a key barrier to storage deployment in that it fails to consider the benefits to the wider energy system, aside from those delivered to the DNO itself.

Five potential business models for distribution-scale storage have been proposed and these are listed in Table 4. Most have been suggested by DNOs and offer them partial or full control over storage assets, which is prohibited by current regulations. For models involving DNOs as merchants and, more generally, Distribution System Operator (DSO) business models, a major concern is to avoid distortion of competition in generation and supply and to respect unbundling requirements. In models related to incentives to charge, competition issues are less important as a third party would be involved in both ownership and operation. However, the DNO is less likely to invest in storage when using this business model because the asset value to the DNO is more uncertain, while the DNO cannot operate the storage to realize its value. This suggests that the benefits to the DNO are not fully represented in this business model. Thus, while the DSO models have regulatory challenges, the incentives models entail far higher commercial and security risk [25]. There remains no consensus over which market players, including DNOs, should be given the ability to control storage devices [24].

Network ownership of energy storage has been trailed in several countries. DNOs in Italy and DSOs in Belgium are allowed to own and operate battery storage, and there is no evidence that this has prevented the competitive functioning of the generation and supply markets. Italy allows DNOs to control battery systems if this choice can be justified throughout a cost-benefit analysis showing that the storage system is the most cost-efficient way to solve the identified problem compared to potential substitutes such as building a new line. Belgium enables DSOs to operate batteries if they do not alter the competitive functioning of markets [25]. This suggests that restrictions on the ownership of storage by distribution-network owners could be somewhat relaxed in other countries, which might be sufficient to encourage the deployments required to underpin innovation in the near term.

\footnotetext{
5 The de minimis requirements are included in the distribution licence and require that: (i) total turnover from nondistribution businesses shall be one of $2.5 \%$ or less of total revenue of the DNOs from distribution; and, (ii) aggregate investments in non-distribution activities shall not be over $2.5 \%$ of the DNOs issued share capital, its consolidated reserves and it share premium.
} 


\begin{tabular}{ll}
\hline \multicolumn{1}{c}{ Model } & \multicolumn{1}{c}{ Description } \\
\hline DNO contracted & $\begin{array}{l}\text { The DNO owns and has full operational control over the storage asset. Before the } \\
\text { storage asset is built, long-term contracts are agreed for the asset's commercial control } \\
\text { in certain periods of time. }\end{array}$ \\
\hline Contracted services & $\begin{array}{l}\text { The DNO offers long-term contracts for services at specific locations with commercial } \\
\text { control in certain periods of time. }\end{array}$ \\
\hline Charging incentives & $\begin{array}{l}\text { The DNO sets the DUoS tariff to create signals that incentivize peak shaving to reflect } \\
\text { the value of network reinforcement. }\end{array}$ \\
\hline DNO merchant & The DNO owns and has full operational control over the storage asset. \\
\hline 'DSO' role & $\begin{array}{l}\text { The DNO owns and has full operational control over the storage asset. In addition, the } \\
\text { DNO is given a regulatory role in balancing and controlling aggregated demand and } \\
\text { generation, taking on an active role as a Distribution System Operator (DSO). }\end{array}$ \\
\hline
\end{tabular}

Table 4. Proposed business model specifications for DNO ownership and operation of storage assets [25].

\section{Market design issues}

Income in wholesale electricity markets is generally determined by the marginal costs of the most expensive generator during each period. Most electricity systems had high reserve generation margins at liberalization and new investments in technologies with high capital and low operating costs, such as renewables, nuclear power and energy storage, have been difficult to justify without subsidies due to the risk of the large up-front investment not being realized [27]. Market design issues tend to differ between electricity systems so this section focuses on the UK markets as a typical case study.

\subsection{Balancing market}

The main barriers to the realization of value of storage in the balancing market are related to the lack of monetization of the full operational benefits that storage can provide when providing balancing energy through the wholesale electricity markets. The price of imbalances, known as cash-out prices, is unlikely to fully reflect the value that storage technologies can offer to the system because it is calculated in a way that only takes into account energy balancing and does not consider wider balancing activities. If the system operator orders the DNOs to decrease demand through brownouts or blackouts in order to balance the system, these balancing activities are not included in the method for calculating cash-out prices.

While cash-out prices are designed to increase during periods of market tightness, they do not tend to increase, to a level that would make storage economic. The current market structure tends to dampen cash-out prices, and the signals and incentives that these are able to provide could be sharper if a wider set of balancing activities were included in the methodology for calculating cashout prices. Cash-out prices do not increase sufficiently during periods of market tightness because they fail to reflect the effective cost of balancing the system. This barrier decreases the value of flexibility and reliability of generation, and hence the potential role of storage in the balancing market.

\subsection{Absence of ancillary markets}

Ancillary markets could be a key source of revenue for storage [28]. The UK offers a typical example. Ancillary services in the UK are operated by the TSO, National Grid, who recovers the cost of procuring these services from generators and end-users. National Grid can issue warnings and rescind payments to generating units whose response is inadequate [29], and this may represent a drawback for energy storage providers since the discharge duration of storage technologies is necessarily limited to the maximum charge level [19]. In addition, updating the energy requirements from ancillary services so that they more accurately reflect the breadth of characteristics underlying storage technologies could be a key means to remove barriers to storage [30]. One approach would be to update ancillary service market requirements to consider more expensive but scalable ESS technologies that can provide system benefits at a smaller bid 
size and shorter energy delivery duration, which would be more appropriate to energy storage devices.

National Grid recently introduced week-ahead tender timescale for the frequency response service that aid the planning of conventional generators [31]. Additional measures to avoid medium-term forecast limitations, such as providing day-ahead tender timescales, and aggregation [32], might encourage the participation of energy storage providers in these markets, while also reducing the costs of providing this service.

Until the introduction of Enhanced Frequency Response (EFR) in the second half of 2016 [33], there were no very fast-response balancing and ancillary markets. The introduction of EFR has seen a $200 \mathrm{MW}$, 4-year tender EFR grid-balancing that responds within one second of registering a frequency deviation, and was met extensively by batteries [34]. However, providers are remunerated only with a capacity payment for providing frequency response in the UK, with no separate payment to reflect performance accuracy of the service. This could be instrumental in improving the value of storage, and has already been already implemented in some US electricity markets [12]. There is a broad movement in the US to modify energy markets to reflect the increasing technical viability of energy storage, underpinned by FERC's reduction of barriers to participation in ancillary services markets and structural changes that allow for pricing that is more sensitive to faster and more accurate frequency regulation.

National Grid are also considering the introduction of an aggregate fast reserve service by nonBalancing Mechanism (BM) service providers in the UK. Several storage technologies could comply with the standard minimum service provision of $50 \mathrm{MW}$ within 2 minutes. More generally, an increasingly flexible market design for reserve markets would enable better allocation of storage capacity to the most needed or valuable service at a particular moment [35].

While the characteristics of storage are suited to the provision of this ancillary service, coordination with other services must be optimized to maximize value realization [1]. There remains a lack of markets in the UK to cover inertial response, governor response and transmission upgrade deferral or avoidance. The lack of potential markets, and the coordination of ancillary service provision, makes it difficult for a storage developer to consider it a benefit to provide these services.

At high voltage levels and under the responsibility of the system operator, trading mechanisms such as contracts for ancillary and balancing services provide opportunities for an economically efficient supply of system flexibility services. In a future in which smart metering and real-time management of distribution networks were present, similar arrangements could be implemented for medium- and low-voltage levels. These services and policy incentives are unlikely to succeed unless they are subject to explicit efficiency, equity, simplicity, consistency, transparency, stability and additivity requirements [36].

\subsection{Capacity market}

Increasing deployment of weather-dependent renewables has led to the introduction of new electricity markets to ensure security of supply, principally through the introduction of capacity markets. Western Australia, which is not connected to the rest of the country's grid, has implemented a capacity mechanism, but prices are often very high [37], which may be interpreted by some as a failure of the capacity mechanism. In the UK, the first capacity auction took place in December 2015 for the provision of capacity in winter 2018/19. Germany has not implemented a large-scale capacity mechanism on the grounds that it is expensive and inefficient, rather relying on the power market.

The UK's Electricity Market Reform (EMR) introduced a capacity market to improve the security of the UK electricity supply. The T-4 capacity market auction was held to secure capacity between 
2020 and 2035, with storage securing $500 \mathrm{MW}$ out of a total commitment of $3.2 \mathrm{GW}$ (so only $15 \%$ of the total capacity) [34].

One challenge for storage providers is that they can only participate directly in the capacity market if their capacity is at least $2 \mathrm{MW}$, unless they bids into the market alongside other generators through an 'aggregation' service [38].

When storage devices are awarded a capacity contract, they must commit to deliver a certain amount of electricity during periods of system stress. There is no time limit over which this delivery must be maintained, thus capacity can be requested at any time during the contracted period. Such an 'open-ended' obligation is a key issue for most storage providers since their discharge duration is necessarily limited to the maximum charge. The storage device must remain fully charged for a long period and suffer parasitic energy losses. If the storage device were entirely discharged before the end of the warning period ${ }^{6}$, its provider would be subject to a heavy penalty [25]. An alternative approach of establishing contracts for defined time limits might provide more secure revenue streams to storage providers and improve their integration within the system.

\subsection{Climate Change Levy}

Some legislation can unexpectedly affect the competitiveness of storage technologies. The Climate Change Levy (CCL) in the UK is a good example. This tax is imposed on energy delivered to nondomestic users with the aim of incentivizing energy efficiency investments and reduced carbon emissions.

The treatment of storage under the UK Climate Change Levy (CCL) remains unclear. Electricity generated from renewable resources ${ }^{8}$ receives a Levy Exempt Certificate (LEC) [26]. The CCL is calculated at the point where electricity is delivered from generation to a distribution or transmission system. However, if export of electricity from a storage device relies on the import of electricity (from a LEC-owning generator) and then the export of this electricity, the issuing of a new LEC at the point of export (since storage is considered a generator) implies a double LEC. Therefore, it could be argued that storage should not be eligible for LECs, which currently represent a substantial barrier to the optimal deployment of storage resources. In a fair market, storage would be treated equally to other generation resources, and the treatment of storage under the CCL arguably does not reflect the value of storage in supporting renewable integration to decarbonize the system.

\section{Categorization of barriers to energy storage deployment}

The major barriers to investment in new energy storage technologies, based on the discussion in the previous sections and on several EU-focused studies [23, 39-41], are in order of perceived importance:

1. a lack of any form of direct support for storage, or lack of clear investment incentives;

2. the classification of storage as a generator although it does not produce a positive net flow of electricity, resulting in unfavorable circumstances, including the presence of open-ended

\footnotetext{
${ }^{6}$ A warning period is issued in the capacity market at least four hours before an anticipated event of system stress, which is designed to give capacity providers a period of four hours in which to supply capacity.

${ }^{7}$ While it is possible to limit the provider's exposure to penalties if the provider offered less than its full capacity to the market, a practice known as 'de-rating', this practice is unlikely to overcome these barriers. Moreover, a storage provider could participate in secondary trading to lower the penalty risk by buying the delivery obligation from another provider, but this is unlikely to reflect the efficient value of storage since it is an expensive method due to the fact that the period in which this may occur is most often a tight market period. Relying on the secondary market is unlikely to represent an efficient solution to decrease non-delivery risk.

8 In the CCL framework, renewable sources of electricity are defined as those not derived from fossil fuels or nuclear, and include waste only if the fossil fuel content is less than $10 \%$ of the total.
} 
contracts for delivery of electricity at any time during long periods in the Capacity Market, via open-ended capacity contracts, which cannot practically be met by storage; and,

3. double and/or uncertain fees for grid access;

4. a lack of recognition of system-wide benefits from storage, including ancillary service performance accuracy payments, such as within the frequency response service, and the absence of non-energy and wider balancing activities in the calculation of cash-out prices in the balancing market.

5. uncertainty regarding the ownership of storage assets;

6. uncertainty regarding the operation of storage assets;

7. a lack of ultrafast-response balancing and ancillary markets;

8. an incomplete, uncertain and complex licensing process;

9. the absence of verified needs for storage declared from an official government source;

10. the absence of verified roles for storage declared from an official government source, including advice on business models and regulatory viability of these, for each domain;

11. the absence of unified and conclusive EU and national legal and regulatory frameworks, and regulatory differences between national markets;

12. Distortions in national energy markets;

13. the lack of policy/regulatory reflection of the substantial dependency of storage on wider electricity system developments;

14. the absence of cost-effectiveness and efficiency of transmission energy planning as storage also depends on the evolution of the network;

15. competition with other balancing and ancillary assets;

16. uncertain public attitudes towards storage (Pidgeon et al., 2014);

These barriers lead to cost allocation issues, distorted compensation mechanisms, lack of price signals and bureaucratic issues and delays [12].

We have identified four barriers to energy storage in EU markets that underpin the investment barriers: (i) classification; (ii) differences in market rules between adjacent balancing and ancillary markets; (iii) lack of ancillary service markets; and, (iv) public sentiment.

Figure 2 shows the links between the four underpinning barriers and the investment barriers. The lack of a separate classification of storage assets contributes to the greatest number of barriers. The investment barriers are interdependent, which at first sight could make effective policymaking more difficult. Yet addressing the four underpinning barriers could contribute to overcoming a number of investment barriers.

Public attitudes are a potentially important factor that may determine whether storage is widely accepted in the UK economy. The engagement of people with energy technologies, both from the demand and supply sides, is a key and sometimes neglected issue that could affect investment. People may find different in-house or large-scale technologies more or less desirable to integrate in their lifestyles or society [42]. 


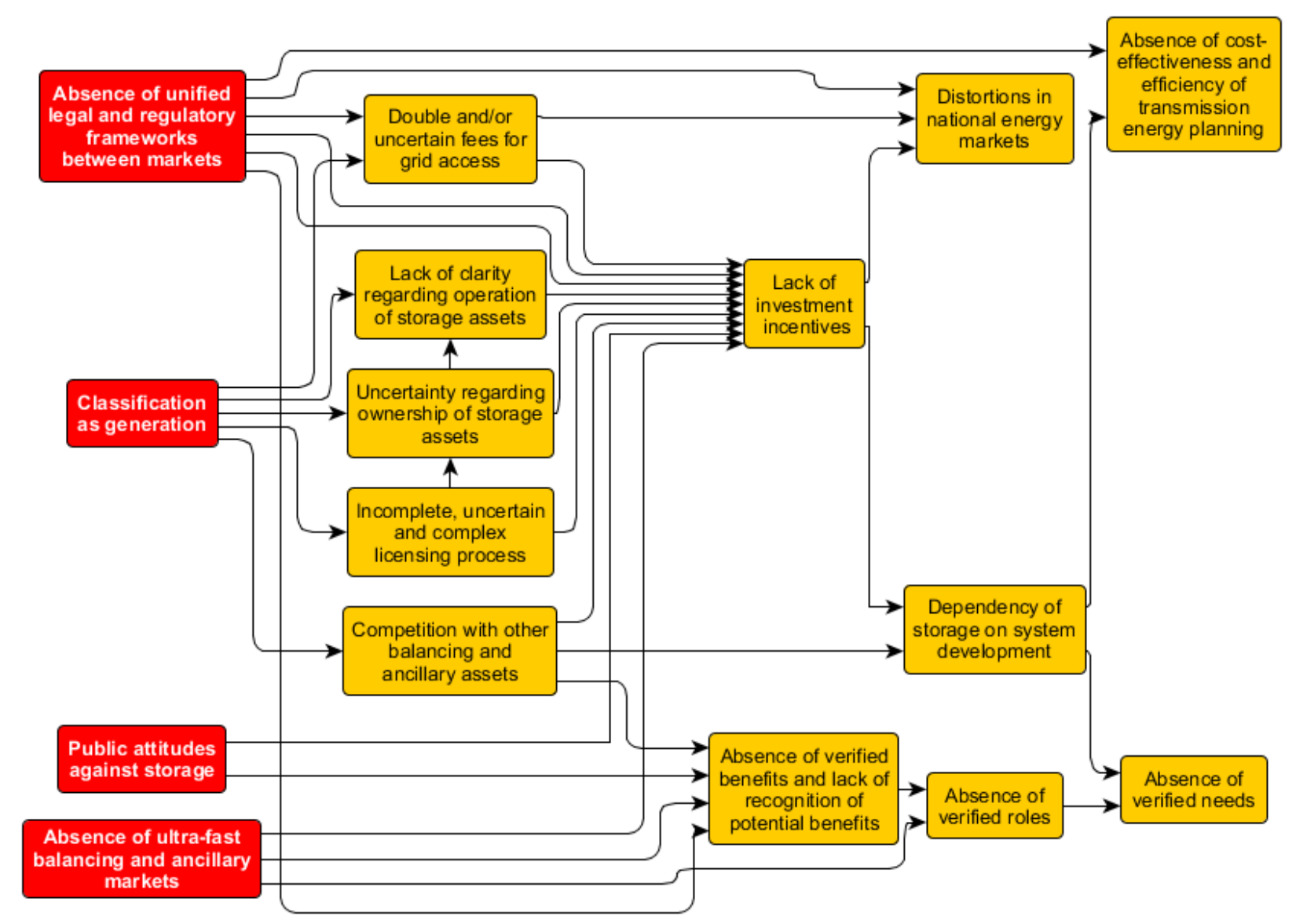

Figure 2. Relationship between barriers to energy storage deployment. Exogenous barriers are colored red.

The barriers to large-scale integration of photovoltaics in the electricity distribution grids are closely related to those affecting storage. A recent paper [43] categorizes options for integrating distributed photovoltaics into three areas: (i) Distribution System Operator (DSO) solutions; (ii) prosumer solutions; and, (iii) interactive solutions [44]. DSO solutions can be deployed by current DNOs because they do not require interaction with prosumers, and typically involve reinforcing the network, and deploying or operating equipment in the distribution networks. Interactive solutions require the cooperation of DNOs and prosumers, and usually require a communication infrastructure to enable the interaction of both parties. Finally, prosumer solutions involve the deployment and/or operation of devices installed at the premises of prosumers to modify, for example, their power injection without the direct intervention of DNOs. The authors conclude that current regulation does not promote the evolution of DNOs to DSOs, or an increase in smart grid investments, since DNOs are in many cases not allowed to have extensive control over modern onsite energy technologies, and that there are missing frameworks enabling DNOs to access advanced technology features such as PV inverter capabilities, which could be useful for voltage control or selective curtailment. In addition, current retail tariffs and price signals so not fully reflect the needs of the local distribution network.

Multiple market drivers suggest that electrical energy storage (EES) systems are going to be essential for future power systems within the next decade, but deployment and regulatory change in European markets is progressing at a slower pace compared to the Californian market. With reference to the market and regulatory frameworks in California and Europe, a recent paper [45] identifies key barriers to EES, particularly emphasising the inadequate market design that benefits traditional technologies, and the lack of need for EES in some jurisdiction in Europe. 


\section{Discussion}

Energy storage is classified as a generation asset in most liberalized electricity markets. Yet, storage technologies cannot generate new electricity and they must rely on generators to gain revenue from providing a host of energy market services. Classification is the most significant exogenous barrier to the deployment of storage resources in electricity markets. We therefore proposed a new definition for electrical energy storage that may contribute to recognizing the potential of storage in shifting electricity in time and that differentiates it from generation with the aim of facilitating the removal of numerous barriers to deployment.

There is a precedent in the gas markets for creating a unique asset definition for storage. Security of supply and system stability is a primary concern not only for gas storage in the gas market, but for electricity as well. While this has concentrated on research capacity margins for generators in the past, a more encompassing approach that considered energy storage, interconnection, demand-side response, network reinforcement and flexible generation would be more suitable to reflect the evolving UK electricity market and would help to reduce the costs of ensuring supply security in the future. The regulatory definition of storage in the electricity system is quite different to that of gas storage in the natural gas market, which is treated as an independent asset [46]. Yet, experience from the gas market suggests that creating such a definition could be insufficient to meet the goal of realizing the value of storage and other complementary technologies to minimize electricity supply costs [23].

The principal issue derived from classifying storage as generation is the imposition of double transmission and distribution network tariffs, which reduce its competitiveness. As storage can increase or reduce network congestion, depending on the network design and the storage location relative to generation and demand, these network charges could be justified in some circumstances but are unlikely to be justifiable in a well-designed system.

Technology choice and scale will depend on whether the electricity system moves towards 'European-wide energy superhighways' or instead toward a system of increasing local energy autonomy, featured also by widespread demand side management, which would likely substantially reduce the need for centralized storage solutions [47].

The case for policy support for storage has divided opinion among stakeholders. Some believe that storage deployment constitutes a 'special case' in need of policy support, whilst others insist that markets can provide the necessary platform to negotiate contracts, which reward storage operators for the range of services they could provide [48].

\subsection{Network operator ownership of storage assets}

Storage may need to queue for a long time behind generation for a connection to the grid even if it can relieve constraints. Valuation issues can be addressed through a more transparent pricing of energy-system services and provision of price signals and control technologies to end users [49]. There is currently a lack of policies that could enable DNOs to transparently demonstrate that other customers in the queue can benefit from storage connecting to the grid by allowing for quicker and cheaper connections through an avoided need for reinforcement. In such cases, DNOs should promote storage. Yet enticing DNOs to promote storage may be a difficult task because, in the absence of these incentives, DNOs may simply see storage as an alternative to network expansion that may reduce their own profitability. Incentives could be provided in the form of heat maps to offer providers useful information about demands throughout the network, which might also incentivize deployment of storage in optimal locations in distribution networks. It remains unclear how network connections will be priced in the future to reflect the unique characteristics of electricity storage. Depending on the generation portfolio, location and choice of storage technology, it could support the electricity system by meeting peak loads, reducing peak network flows and hence managing network constraints. One approach for the Government to consider 
would be charging models and network connection tariffs that reflect the size, use and location of the storage connection [12].

\subsection{New markets for energy storage}

Energy storage is unable to compete with flexible generation in existing UK electricity markets. Establishing new markets that reward storage for their non-energy benefits ${ }^{9}$ to the system, or the ultra-fast responding characteristics that some storage technologies can provide, would open up a market. Proposed market changes such as the provision of enhanced frequency response and aggregate fast reserve services could provide new opportunities for storage. Realizing the potential value of storage to the balancing market has proven difficult, and even the new Capacity Market has features such as an effectively open-ended delivery obligation that affects the viability of storage in the market. Energy storage technologies could make these important contributions if effective innovation, underpinned by deployment into electricity markets, can reduce their high capital costs. The scale of cost savings from adopting storage technologies to the UK derive from avoided fossil fuel costs, a better utilization of generation and network assets and a superior performance in providing network services. By these means, the impact of storage has been demonstrated to potentially very large, reaching up to an order of multiple £bns/year with additional savings of comparable orders are to be achieved if storage is deployed early [11]. Accelerated innovation is required to reduce these costs, which involves deploying technology into electricity systems in order to "learn-by-doing".

Emerging energy storage technologies would benefit from a friendlier market environment. Energy storage is an important part of the UK's industrial policy and the UK is at the forefront of developing a number of novel energy storage technologies with high export potential. However, the required innovation is unlikely to happen unless a regulatory path is created to facilitate the deployment of energy storage in the existing electricity system.

The barriers for active deployment of energy storage through electric vehicles is discussed in [50] from technology, infrastructure, regulatory and market perspectives. Regulatory and policy barriers are thought to present a greater challenge than technology and infrastructure issues due to the large diversity of distribution systems and respective regulatory frameworks across markets.

\subsection{Subsidies for energy storage deployment}

Although novel storage technologies have recently taken a small role in several countries, for example in ancillary markets in the UK, it is currently difficult to justify deploying storage as both network reinforcement and flexible generation are currently cheaper for most system and electricity market requirements. Low-carbon electricity generators with high capital costs have required subsidies to compete, in the form of generation quotas or strike prices, and energy storage technologies face similar challenges.

Storage in the UK is not supported by specific subsidies to support its deployment, which could represent a barrier per se, decreasing investor confidence. Experience from other technologies, e.g. solar PV and wind, suggests that growth of a market for a technology can reduce costs, and incentives can play an important part in creating that market.

The California market has been modified to encourage the deployment of novel energy storage technologies. California enacted a law in October 2010 requiring the California Public Utilities Commission (CPUC) to establish appropriate 2015 and 2020 energy storage procurement targets for California load serving entities, on condition that they were cost-effective and commercially viable by October 2013. Furthermore, specific storage targets were set by the CPUC for each electric utility and type of domain (i.e. transmission; distribution; end-user) [12], which has led to an unprecedented rate of deployment of storage across the market. These initiatives are expected to

\footnotetext{
${ }^{9}$ Non-energy benefits are benefits beyond energy savings, such as the integration of renewables or avoided emissions.
} 
decrease the risk that electric utilities face when investing in energy storage [51]. China and France have recently also implemented a similar obligation.

In addition, storage may be subject to tariff-based barriers, such as the fact that utilities typically cannot offer a rate structure for high-quality uninterruptible power to those companies that need such security, yet they can offer interruptible tariffs to those who are willing to have their power supply curtailed in times of shortage [52].

\subsection{Limitations to this analysis and future work}

This study identifies a range of market barriers to deploying electrical energy storage. There is a need to estimate empirically the extent of the market failures and inefficiencies due to these barriers. Applying a whole electricity system modelling approach that incorporated a policy module could contribute toward explaining these inefficiencies and applying a regulatory policy module that empirically took into account these barriers would help to better understand and reduce the influence of these barriers on the incentives for storage deployment. More generally, we recommend that market authorities identify the relationships between barriers, in order to enable a deeper and smoother removal of barriers to deployment, in the spirit of the analysis provided in this paper.

\section{Conclusions}

Although energy storage is recognized as a key technology, current regulations could prevent storage from developing into an optimally performing flexibility option for electricity markets. Our work identified and qualitatively analyzed the major regulatory barriers that could constrain the system-optimal deployment of storage resources in the UK, the majority of which apply to most liberalized electricity markets across the globe.

A key challenge is the treatment of storage technologies as generation subsets, which creates numerous uncertainties. We argue that this issue leads to additional regulatory barriers, and show that resolving this issue would facilitate the removal of numerous barriers to deployment. These barriers notably lead to cost allocation issues, distorted compensation mechanisms, lack of price signals and bureaucratic issues and delays.

We defined the 'exogenous' barriers to energy storage, or barriers that are unaffected by other barriers, which are identified as: regulatory classification, differences in market rules between adjacent balancing and ancillary markets, and a lack of system and non-energy ancillary service markets. These barriers are shown to cause multiple additional barriers and are interdependent, which makes sensible policymaking difficult by nature.

While storage has only very recently began securing contracts for the Enhanced Frequency Response (EFR) service and the Capacity Market, major regulatory and market design barriers are preventing storage from realizing their full value throughout the electricity system. The extent of deployment will depend on the development of independent system operators that are able to allocate grid services efficiently to non-conventional resources. While such an activity necessitates substantial control of these assets by the system operator, it will likely require new market mechanisms that incentivize these resources to participate more freely in markets for grid services.

Various initiatives are currently underway and may help address the current difficulty of storage resources in accessing key revenue streams. While market changes such as the EFR frequency response and aggregate fast reserve services could provide important revenue for storage, additional efforts will be required. In particular, further research is needed to understand the ways in which system and non-energy benefits could be realized, inter-temporally dispatched and managed. Policies such as flexible connection agreements [53] could represent the first step toward monetizing these less conventional benefits. Additional policies will also be required to 
minimize the distortion of value to storage from aggregation services, which will in turn depend on the degree of market centralization.

The removal of barriers to storage is directly associated with its treatment as an integral part of the electricity system. In such a setting, system efficiency will be maximized if market players are incentivized to view the technology as complementing networks and generation assets, rather than competing with them on the margin.

\section{Acknowledgements}

The authors are grateful to Keith Bell for advice on our proposed definition of electricity storage. They also thank the reviewers for useful suggestions that improved the paper.

This work was supported by the UK Engineering and Physical Research Council (EPSRC) through the Realising Energy Storage Technologies in Low-carbon Energy Systems (RESTLESS) project [grant number EP/N001893/1]. The project is part of the EPSRC Energy Superstore Hub and is associated with the UK Energy Research Centre (UKERC).

\section{References}

[1] Strbac G, Aunedi M, Pudjianto D, Djapic P, Teng F, Sturt A, et al. Strategic Assessment of the Role and Value of Energy Storage Systems in the UK Low Carbon Energy Future. Energy Futures Lab report for the Carbon Trust; 2012. Available at: www.carbontrust.com/media/129310/energystorage-systems-role-value-strategic-assessment.pdf.

[2] Dell RM, Rand DAJ. Energy storage - a key technology for global energy sustainability. Journal of Power Sources. 2001;100:2-17.

[3] BIS, Willetts D. Policy Exchange pamphlet. Department for Business, Innovation \& Skills. London, UK; 2013.

[4] HM Government. Green Paper: Building Our Industrial Strategy. London, UK: 2017.

[5] Grübler A, Nakićenović N, Victor DG. Dynamics of energy technologies and global change. Energy Policy. 1999;27:247-80.

[6] Onaiwu E. How does bilateral trading differ from electricity pooling?: Universisty of Dundee; 2009.

[7] Ofgem. Final report of Workstream Six of the Smart Grid Forum - The customer-focused smart grid: Next steps. Office for Gas and Electicity Markets. London, UK; 2015. Available at: https://www.ofgem.gov.uk/publications-and-updates/final-report-workstream-six-smart-grid-forumcustomer-focused-smart-grid-next-steps;.

[8] DECC. Towards a Smart Energy System. Department of Energy and Climate Change; 2015. Available at: https://www.gov.uk/government/uploads/system/uploads/attachment_data/file/486362/Towards_a_ smart_energy_system.pdf.

[9] European Commission. Review and analysis of EU wholesale energy markets: Historical and current data analysis of EU wholesale electricity, gas and CO2 markets. 2008.

[10] National Renewable Energy Laboratory. Overgeneration from Solar Energy in California: A Field Guide to the Duck Chart. 2015. 
[11] Carbon Trust. Can storage help reduce the cost of a future UK electricity system? . London, UK: 2016.

[12] U.S. Department of Energy. Grid Energy Storage Report. 2013.

[13] Minelli G, Pandolfi L, Jacini C, Galli N, Tonetti R, Tampieri A, et al. National Framework Italy. 2013. Available at: http://www.alpstore.info/Download.html,.

[14] DECC. Chapter 5: Electricity. Department of Energy and Climate Change. London, UK; 2015. Available at: https://www.gov.uk/government/uploads/system/uploads/attachment_data/file/552059/Chapter_5_ web.pdf.

[15] Brandon N, Edge J, Aunedi M, Barbour E, Bruce P, Chakrabarti B, et al. UK Research Needs in Grid Scale Energy Storage Technologies. Energy SuperStore; 2016.

[16] Taylor P, Bolton R, Stone D, Zhang X-P, Martin C, Li Y, et al. Pathways for energy storage in the UK. Report for the Centre for Low Carbon Futures; 2012.

[17] European Commission. Energy Storage - Proposed policy principles and definition. 2016.

[18] BEIS, Ofgem. A smart, flexible energy system: A call for evidence. Department for Business, Energy and Industrial Strategy, Office of Gas and Electricity Markets. London, UK; 2016. Available at:

https://www.gov.uk/government/uploads/system/uploads/attachment_data/file/576367/Smart_Flexi bility_Energy_-_Call_for_Evidence1.pdf.

[19] International Energy Agency. Technology Roadmap Energy Storage. 2014.

[20] Barbour E, Wilson IG, Radcliffe J, Ding Y, Li Y. A review of pumped hydro energy storage development in significant international electricity markets. Renewable and Sustainable Energy Reviews. 2016;61:421-32.

[21] Ofgem. RIIO Factsheet. Office for Gas and Electicity Markets. London, UK; 2013.

[22] National Grid. Connection and Use of System Code. Applicability of sections and related agreements structure. 2015.

[23] Directorate General for Internal Policies. Energy Storage: Which Market Designs and Regulatory Incentives Are Needed? : European Parliament; 2015. Available at: http://www.europarl.europa.eu/RegData/etudes/STUD/2015/563469/IPOL_STU(2015)563469_EN. pdf;:

[24] ENTSO-E. 2014 Ten-Year Network Development Plan. European Network of Transmission Operators for Electricity. Brussels, Belgium; 2014.

[25] UK Power Networks. Electricity storage in GB. Interim Report on the Regulatory and Legal Framework Smarter Network Storage Low Carbon Network Fund 2013.

[26] Pöyry. Storage business models in the GB market. 2014.

[27] Kirby B. Ancillary Services: Technical and Commercial Insights. USA: Wartsila; 2007.

[28] National Grid. Balancing Principles Statement. Procurement Guidelines2015. Available at: file:///C:/Users/tjmscas/Downloads/Procurement\%20Guidelines\%20v14.0\%20Effective\%20from\%2 01\%20April\%202016.pdf;. 
[29] Eurelectric. EU Islands: Towards a Sustainable Energy Future. Brussels, Belgium: 2012. Available at: http://www.eurelectric.org/media/38999/eu_islands__towards_a_sustainable_energy_future_-_eurelectric_report_final-2012-190-0001-01-e.pdf.

[30] Anuta OH, Taylor PC, Jones D, McEntee T, NS W. An international review of the implications of regulatory and electricity market structures on the emergence of grid scale electricity storage. Renewable and Sustainable Energy Reviews. 2014;38:489-508.

[31] National Grid. Firm Frequency Response: Market Information. 2017. Available at: http://www2.nationalgrid.com/UK/Services/Balancing-services/Frequency-response/Firm-

Frequency-Response/Firm-Frequency-Response-Information/.

[32] UK Power Networks. Business model consultation. Smarter Network Storage; 2012.

[33] National Grid. Enhanced Frequency Response. Invitation to tender for pre-qualified parties2016. Available at: file://C:/Users/tjmscas/Downloads/Enhanced\%20Frequency\%20Response\%20ITT\%20v1_1.pdf;.

[34] Solar Power Portal. Energy storage: More tenders, government priorities and solving the revenue stream dilemma2017.

[35] Wasowicz B, Koopmann S, Dederichs T, Schnettler A, Spaetling U. Evaluating regulatory and market frameworks for energy storage deployment in electricity grids with high renewable energy penetration2013.

[36] Eid C, Codani P, Perez Y, Reneses J, Hakvoort R. Managing electric flexibility from distributed energy resources: A review of incentives for market design Renewable and Sustainable Energy Reviews. 2016;64:237-47.

[37] Government of Western Australia. Electricity Market Review Final Report: Reforms to the Reserve Capacity Mechanism Department of Finance Public Utilities Office; 2016.

[38] DECC. Feed-in Tariff: Guidance for Renewable Installations. Department of Energy and Climate Change; 2015.2 Available https://www.ofgem.gov.uk/sites/default/files/docs/2015/06/feedin_tariff_guidance_for_renewable_installations_v9_0.pdf;

[39] WIP. European Regulatory and Market Framework for Energy storage Infrastructure. Store; 2013.

[40] EU Commission. The future role and challenges of energy storage. Brussels, Belgium: 2012.

[41] European Parliament. Energy Storage: Which Market Designs and Regulatory Incentives Are Needed?2015.

[42] Pidgeon N, Demski C, Butler C, Parkhill K, Spence A. Creating a national citizen engagement process for energy policy. Proceedings of the National Academy of Sciences. 2014;111:13606-13.

[43] Mateo C, Frías $P$, Cossent R, Sonvilla $P$, Barth B. Overcoming the barriers that hamper a large-scale integration of solar photovoltaic power generation in European distribution grids. Solar Energy. 2017;153:574-83.

[44] Vandenbergh $M$, Craciun D, Helmbrecht $H$, Hermes $R$, Loew $H$. Technical solutions supporting the large scale integration of photovoltaic systems in the future distribution grids. 22nd International Conference on Electricity Distribution. Stockholm, Sweden2013. 
[45] Castellano Ruz F, Pollitt M. Overcoming barriers to electrical energy storage: Comparing California and Europe Cambridge Working Paper in Economics 1629. 2016.

[46] Ofgem. Guidance on the regulatory regime for gas storage facilities in Great Britain. Office for Gas and Electicity Markets. London, UK; 2015.

[47] Think. Electricity Storage: How to Facilitate its Deployment and Operation in the EU2012.

[48] Grunewald P, Cockerill T, Contestabile M, Pearson P. The socio-technical transition of distributed electricity storage into future networks-system value and stakeholder views. Energy Policy. 2012.

[49] Sioshansi R, Denholm P, Jenkin T. Market and Policy Barriers to Deployment of Energy Storage. Economics of Energy and Environmental Policy, 2012; 1(2): 47. 2012;1.

[50] Knezovi K, Marinelli M, Zecchino A, Andersen P, Traeholt C. Supporting involvement of electric vehicles in distribution grids: Lowering the barriers for a proactive integration. Energy. 2017;134:458-68.

[51] Anaya K, Pollitt M. Electrical Energy Storage: Economics and Challenges. Energy World Energy Institute; 2015.

[52] McDowall J. Status and Outlook of the Energy Storage Market. IEEE. 2007.

[53] Energy Networks Association. Flexible Connections. London, UK: 2016. Available at: http://www.energynetworks.org/electricity/futures/flexible-connections.html. 